\title{
Multi-epitope Anti-folate Receptor Peptide Vaccine TPIV 200
}

National Cancer Institute

\section{Source}

National Cancer Institute. Multi-epitope Anti-folate Receptor Peptide Vaccine TPIV 200.

NCl Thesaurus. Code C128898.

A peptide vaccine containing five immunogenic peptide epitopes of the human folate receptor 1 (FOLR1; FR-alpha), with potential immunomodulating and antineoplastic activities. Upon intradermal administration, multi-epitope anti-folate receptor peptide vaccine TPIV 200 may induce a cytotoxic T-lymphocyte (CTL) response against FR-alphaoverexpressing tumor cells. FR-alpha is a high-affinity folate-binding protein and a member of the folate receptor family; this receptor is overexpressed in various cancer cell types. 